Medical treatment involving hospitals, doctors and ambulances was estimated to cost $£ 10$ million. There are no figures available for the costs incurred when vehicles are delayed by accidents and no estimate was included in the final accident costings. $\mathrm{Mr}$ Dawson suggested, however, that half an hour's delay per vehicle per year would cost the community $£ 6$ million.

The total measurable cost of accidents in 1963 came to $£ 196$ million. By 1965 this total had risen to $£ 246$ million, and the average measurable cost per accident had risen to $£ 820$ from the 1963 figure of $£ 710$ for all areas. This particular average is obtained by dividing the total cost of all accidents by the number of accidents in which personal injury occurred. Although this is not necessarily the perfect figure, it makes the best use of the available information. When road improvement schemes are evaluated, for example, public safety is of prime importance, and statistics are compiled with this in mind.

Subjective costs of fatal and serious injuries, which Mr Dawson has introduced for the first time, have been set at $£ 5,000$ for a fatality and $£ 200$ for a serious injury. In some cases, when a person is supported by the state, their death might result in financial gain to the community. The minimum value that can be put on people's lives is thus the amount of money the community pays to support them. It is on this premise that Mr Dawson made his calculation. When subjective costs are included in the total cost of accidents, the figure for 1965 rises to $£ 306$ million, $£ 60$ million above the measurable figure. This higher total produces the average cost per accident of $£ 1,020$ for all areas. When broken down into categories of road conditions, the estimates put urban accidents at $\mathfrak{£} 880$, those in rural areas at $£ 1,510$, and those on motorways, where higher speeds cause greater damage, at $£ 2,610$.

\section{Star Prizes}

THE Royal Astronomical Society announced on January 12 the award of its Gold Medal to Professor Fred Hoyle for his contributions to theoretical astrophysics, especially the theory of stellar structure, nucleosynthesis and cosmology.

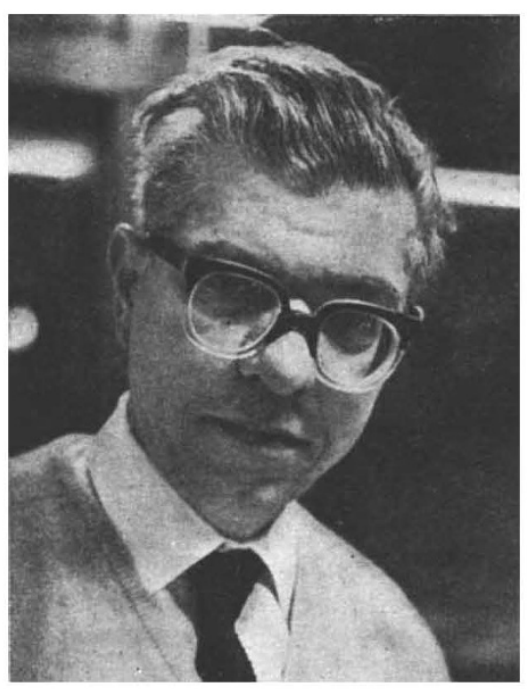

Professor Fred Hoyle.
Dr W. H. Munk has also received a Gold Medal for his contributions to oceanography and to the study of the variation of the rotation of the Earth.

The Eddington Medal has gone to Drs R. HanburyBrown and R. Q. Twiss for their invention and theoretical study of the intensity interferometer. This instrument has now led to accurate measurements of the angular diameters of a series of stars.

The Jackson-Gwilt Medal and Gift has been awarded to Dr J. G. Porter in recognition of his work on the orbits of comets and meteors and of his activities in the promotion of public interest in astronomy.

\section{Fewer Fellows}

THE decision reached in November 1967 to reduce the number of Harkness fellowships from sixty-five to twenty has been received in Britain without joy. These fellowships, named after Mr Edward S. Harkness, have enabled deserving young men and women from the countries of Western Europe and from New Zealand and Australia to continue their studies in the United States. The influence of the fellowships has furthermore extended to the growing number of departments in European universities concerned with American studies, where the staff are mainly former fellows.

The value of the fellowship varies, and the Commonwealth Fund in London says that it was difficult to quote an average figure. Despite the fact that the total value of the fellowships amounts to only oneseventh of the Commonwealth Fund-\$7,059,190 for 1967-the directors of the fund in New York want to channel more money into medical research, which already receives the lion's share. At least Britain will not suffer quite as much as the other countries and from 1969 onwards will, in fact, be the only country to receive fellowships, with a reduction in the number from thirty to twenty.

There remains the question of where the axe will fall next. The number of fellowships awarded by the National Institutes of Health to United States postgraduates for research in Britain may be the next to be reduced or cut completely.

\section{Sharing out Teachers}

ACCORDING to an announcement made by Mr Patrick Gordon Walker on January 18, an improvement is expected in the total supply of school teachers and in their distribution in shortage areas. This week, a circular has been sent by the Department of Education to local education authorities, informing them what their allocation of certain kinds of teachers will be for next autumn. One thing which the circular points out is that some local authorities have been recruiting more than their share of teachers, so that some areas have gone short: authorities are therefore urged to exercise "closer control". The circular also stresses the importance of part-time teachers and of married women returning to teaching.

The fact that definite steps needed to be taken to improve the distribution of teachers was realized in 1956. This led to the introduction of a quota which laid down the total number of teachers to be employed by a local education authority. This quota scheme is confined to schools which are maintained by local education authorities and is a voluntary rationing 